\title{
Impact of Covid-19 Pandemic on Small and Medium-Sized Enterprises (SMEs) in Azerbaijan
}

\author{
Qi Xu, Shamil Abbasov* \\ Business School, Zhengzhou University, Zhengzhou, China \\ Email: xuqiphd@zzu.edu.cn, *shamilabbasov@gs.zzu.edu.cn
}

How to cite this paper: $\mathrm{Xu}, \mathrm{Q} ., \mathrm{A}$ Abbasov, S. (2021). Impact of Covid-19 Pandemic on Small and Medium-Sized Enterprises (SMEs) in Azerbaijan. Open Journal of Business and Management, 9, 2759-2771.

https://doi.org/10.4236/ojbm.2021.96153

Received: September 9, 2021

Accepted: October 31, 2021

Published: November 3, 2021

Copyright $\odot 2021$ by author(s) and Scientific Research Publishing Inc. This work is licensed under the Creative Commons Attribution International License (CC BY 4.0).

http://creativecommons.org/licenses/by/4.0/

\begin{abstract}
The COVID-19 pandemic has had a significant impact on the economy of Azerbaijan. Small and Medium-Sized Enterprises (SMEs) are one of the major victims of COVID-19. The aim of this article was to assess the impact of COVID-19 pandemic on Small and Medium-Sized Enterprises (SMEs) operating in Azerbaijan and provide policy recommendations for policymakers to help SMEs impacted by the pandemic to survive and thrive through COVID19. Quantitative research method was deployed in this study with an online questionnaire for collecting data from SMEs operating in different regions and cities of Azerbaijan. The collected data was analyzed through descriptive statistics analysis approach. The results of the study indicate that the COVID-19 pandemic has massively affected small and medium enterprises. Approximately $92.96 \%$ of the enterprises participating in the research study showed that COVID-19 has either extremely negatively or negatively impacted the businesses operations. The results of the survey also showed that the tourism (26.60\%), restaurant and cafe $(22.10 \%)$ and education sector (13.60\%) are among the most negatively affected by COVID-19 pandemic while pharmacies $(0.2 \%)$, insurance $(0.8 \%)$ and agriculture (1.2\%) are among the least affected by the pandemic. Various policy recommendations were suggested for policymakers to ease the burden on SMEs, based on the research findings.
\end{abstract}

\section{Keywords}

COVID-19, Small and Medium-Sized Enterprises (SMEs), Azerbaijan, Policy Recommendations

\section{Introduction}

On 28 February 2020, Azerbaijan's health authorities announced the first posi- 
tive case of COVID-19 in the country. According to data from World Health Organization, Azerbaijan has recorded approximately 334,747 COVID-19 confirmed cases with over 4945 deaths from 3 January 2020 to 8 June 2021 (WHO, 2021). In a bid to contain the COVID-19 situation, the Azerbaijan government introduced a state of emergency, which entailed measures such as the closure of all businesses except for the banks, pharmacies, and grocery stores. In addition, the Azerbaijan government imposed several restrictions and containment measures to control COVID-19 from spreading across the country. Some of the restriction measures adopted by the Azerbaijan government include quarantine, social distancing, closure of businesses, barning of local and international travel, and limitation of social movements. However, all steps adopted by the Azerbaijan government to contain the COVID-19 situation have resulted in a sharp decline in demand and supply.

It is undeniable that the outbreak of the COVID-19 epidemic has thrown Azerbaijan's economy into disarray. The restriction and containment measures adopted by the Azerbaijan government do affect not only large industries such as tourism and hospitality, transport and logistics, and banking system, but also small and medium-sized businesses (Akbulaev et al., 2020). Given the fact that no clear roadmap to measure the real impact of the COVID-19 epidemic on Azerbaijan's economy, the spread of the pandemic has resulted in a decline in tax collection, a high rate of unemployment, a drop in demand and supply of goods and services, and closure of hotels and other tourism centers. Furthermore, approximately 1.2 million workers have lost their jobs due to quarantine and lockdown (Abasli, 2020). In particular, the noticeable industries mainly impacted by this pandemic include hospitality and tourism, travel, manufacturing, retail, and food service. Notably, the pandemic has thrown the Azerbaijan economy into a great recession and projects to deteriorate in the near future.

The economic growth and development in Azerbaijan primarily depend on varying degrees of SMEs. Following the manat's devaluation in 2015, the Azerbaijan government has adopted policies to strengthen and promote small and medium-sized enterprises and improve the state of entrepreneurship in the country (Bayramov et al., 2017). Against the devaluation background of economic interest, the Azerbaijan government had adopted a clear framework for the general production of consumer goods to support the growth of small and medium businesses and strengthen their economic diversification. In addition, before the COVID-19 outbreak, the government had signed Decree No. 1771 to improve the growth and development stability of small and medium-sized enterprises in Azerbaijan (Mahmudova, 2019). Small and medium-sized enterprises account for $90 \%$ of Azerbaijan's economic diversification and act as back-born for economic growth and development according to (Bayramov et al., 2017).

The impact of COVID-19 epidemic is inevitable in Azerbaijan. Small and medium-sized enterprises have suffered more compared to large firms. SMEs 
have experienced a sharp decline in supply chain disruptions, demand, a shortage of raw materials, delays in the transportation of raw materials and cancellation of export orders following the economic recession in the country (Abasli, 2020). The closure of businesses has resulted in major losses, especially in the hotel and retail groceries. The decline in supply and demand has further increased the unemployment rate as approximately $30 \%$ of the small and medium-sized businesses have lost their jobs (Akbulaev et al., 2020). Furthermore, SMEs have gone through a difficult economic situation and the uncertainty period due to the fact that the government has been reluctant to offer them supportive incentives such as tax relief, financing of suppliers, direct financial assistance, and tax credit.

\subsection{Research Questions}

This paper strives to find answers to the following three research questions:

RQ1. How the COVID-19 pandemic has affected the small and medium-sized enterprises in Azerbaijan?

RQ2. Which business sectors are impacted the most and least by the COVID19 pandemic?

RQ3. What measures could be taken to help SMEs impacted by the COVID19 pandemic survive and thrive through COVID-19 and beyond?

\subsection{Research Objectives}

In answering these research questions, this paper aims to assess the impact of COVID-19 pandemic on small and medium-sized enterprises (SMEs) and provide policy recommendations to assist SMEs in reducing their business losses and surviving through the pandemic by adopting an exploratory methodology with reviewing the available literature and quantitative methodology with analyzing the data collected from 75 SMEs operating in different regions of Azerbaijan by conducting an online questionnaire.

\subsection{Research Significance}

SMEs has positive contribution to the economy of Azerbaijan by increasing employment, gross value added, turnover and foreign trade activities. They are considered as one of the main players of growth and development of the country's economy. Nevertheless, a COVID-19 pandemic caused SMEs activity to become hampered and no longer able to run. There is a very limited study on the impact of COVID 19 on the SMEs in Azerbaijan, so it is necessary to investigate the impacts of COVID 19 on SMEs and challenges they meet during the pandemic. This study contributes to the growing literature on SMEs' practices and external support in times of crisis. Also, this research will make a significant contribution for SMEs to overcome the challenges faced and for the policy makers in identifying strategies required to respond to the impact of the ongoing pandemic on SMEs. 
This paper is structured as follows: Section 2, literature review, discusses the impact of the COVID-19 pandemic on SMEs in different countries around the world. Section 3 covers Methodology. Designed questionnaire was adopted using quantitative research approach as a research methodology. Section 4 covers study results and discussion. The results and discussion are based on survey and data collected. Finally, Section 5 delves into recommendations for policymakers to help SMEs impacted by the pandemic to survive and thrive through COVID-19 and beyond based on questionnaire findings and the available literature on the experience of different countries.

\section{Literature Review}

In this section, available literature on impact of COVID-19 on small and medium sized enterprises in different countries and regions has been reviewed, as no research has been done on the impact of COVID-19 on small and medium sized enterprises in Azerbaijan yet.

To find out the effects of COVID-19 on small and medium-sized enterprises in the Middle East and North Africa (MENA) and Turkey, RAND Europe conducted an online survey from May 4 to May 21, 2020 and focused on businesses owned by refugees, women and young entrepreneurs. 171 SME owners responded to the survey. The majority of respondents are from Jordan, Lebanon, Palestine and Turkey. 79\% of respondents in MENA and Turkey said the overall impact of the pandemic on their business activities was negative. More than half of respondents said that pandemic had a significant negative impact on all areas of their business, including, demand and supply chain, financial and distribution channels. And yet, $61 \%$, of those surveyed, think their business will not last more than 4 months if this continues. $85 \%$ of respondents think that they will not be able to withstand more than a year (Hoorens, Hocking, \& Fays, 2020). This result coincides with similar results in a survey conducted by the United Nations Development Program (UNDP) for enterprises in Turkey. Thus, 96\% of respondents said that the pandemic is a serious threat to the business of entrepreneurs (UNDP, 2020).

A similar survey was conducted in the Asia-Pacific region by Youth Co: Lab. To find out how the coronavirus pandemic is affecting business owners, and how these entrepreneurs are responding, they surveyed 410 young entrepreneurs from various industries in 18 countries. According to the research, as of March 31, 2020, 9 out of 10 entrepreneurs in the Asia-Pacific region, $86 \%$ said that COVID-19 pandemic had a negative effect on their business. 1 in 4 of those affected, said they stopped working entirely and 1 in 3 said they had a major slowdown in their work. The percentage results are as follows:

- Completely stopped $21.96 \%$,

- A significant slowdown $27.65 \%$,

- A Moderate decrease 21.19\%,

- A slight drop $14.99 \%$, 
- A Positive effect $6.20 \%$,

- No effect $8.01 \%$.

If we look at Europe, we see that in Europe, SMEs represent $99.8 \%$ of the entire market. It accounts for two-thirds of jobs. Moreover, small and medium businesses represent nearly $60 \%$ of the value-added growth (Muller et al., 2019). On the demand side of the economy, demand for SMEs has declined significantly because of the cessation of several Global Value Chains (GVCs) and declining consumer confidence in industries due to COVID-19. On the supply side, SMEs face material and technical difficulties due to labor shortages and transport disruptions (Juergensen, Guimón, \& Narula, 2020).

Following the latest survey study conducted in Germany, 58\% of the SMEs have recorded an average of $50 \%$ drop in income, while $85 \%$ of SMEs in the Netherlands are experiencing financial difficulties due to COVID-19. $40 \%$ of companies in Belgium reported $75 \%$ or more reduction in revenue. In Portugal, $37 \%$ of businesses reported more than $50 \%$ reduction in production (Maulana, 2020).

In the United Kingdom, where small and medium-sized enterprises account for approximately 50 percent of corporate income and nearly 44 percent of the entire country's workforce, the COVID-19 has resulted in market stagnation and recession according to a recent McKinsey survey of SMEs. The COVID-19 epidemic has significantly weakened the economic states of many countries facing various governments to turn on SMEs for revenue collection. The findings of the survey indicated that economic sectors primarily affected by the COVID-19 pandemic most include construction, agriculture, transport, and logistics. $90 \%$ of small and medium businesses have reported declining profits due to decreased sales in these sectors. In contrast, SMEs in finance, science and education, insurance are the least affected (Albonico \& Sharma, 2020).

The situation is no different when we look at the situation of SMEs in Canada. According to a survey conducted by the Research and Market Intelligence Unit of the Business Development Bank of Canada (BDB), entrepreneurs have strongly felt the impact of COVID-19. 90\% of respondents said it had a negative impact. $3 \%$ said that COVID-19 had a positive effect, while $6 \%$ said, "it has not had an effect so far" (BDC, 2020).

Enesi and Ibrahim (2021) studied the effect of COVID-19 pandemic on the performance of SMEs in Abuja, Nigeria and provided recommendations on how SMEs can improve and perform effectively during this falling economy and function more efficiently in the face of the pandemic's severe hurdles. 10 SMEs in Abuja Municipal Area Council with 100 respondents were purposefully chosen to elicit insights on the impact of the COVID-19 epidemic on their enterprises in the study. According to the findings of the analysis, the COVID-19 pandemic has had the following effects: low revenue or income creation, loss of qualified employees due to salary reductions, lack of patronage, and a lack of sincerity on the part of the government to diminish the pandemic's prevalence. 
SMEs frequently encounter issues such as the inability to pay salaries, repay loans, and pay rent. The majority of respondents proposed that the government should implement well-managed and structured palliative care programs, poverty alleviation initiatives, lower interest rates, loosen loan terms, and defer tax payments.

\section{Methodology}

The primary objective of this research is to examine the impact of COVID 19 pandemic on small and medium-sized enterprises in Azerbaijan using quantitative research approach. Due to lockdown and quarantine in Azerbaijan, the data was collected through an online questionnaire delivered via various social media platforms (Facebook, Whatsapp) and e-mail to the target SMEs in Azerbaijan. The questionnaire was sent to 75 entrepreneurs in major cities and regions in Azerbaijan. The questionnaire was designed to be easy and simple to understand and answer with 20 questions in total. The questionnaire was conducted from February 6 to May 7, 2021. The questionnaire was directly related to the impact of the COVID-19 on the SMEs and support policies of Azerbaijan government. The collected data was analyzed by employing a descriptive statistics analysis approach.

\section{Sample Description}

The small and medium businesses selected for this survey were from various business databases. The number of enterprises included in the survey was $(\mathrm{n}=$ 75) covered in the service, industry, and agriculture sectors. In terms of percentage, the service sector represented $(71.26 \%$, industry $(22.20 \%)$, and the agriculture sector represented (6.54\%). Table 1 below demonstrates the percentage composition of the Azerbaijan economic regions, designation of participants, total number of employees, annual sales turnover for the enterprises involved in this study.

A vast majority of participants belong to Baku (68.34\%) followed by Absheron (8.54\%), Aran (8.04\%), Ganja-Gazakh (5.53\%), Sheki-Zagatala (5.53\%), GubaKhachmaz (1.53\%), Mountainous Shirvan (1.53\%) and Lankaran (1.02\%). Around $35 \%$ of the respondents are the owners of SMEs, $14.05 \%$ directors, $25.43 \%$ managers and $14.48 \%$ working on an assistant manager position. In terms of the number of employees, the survey results show that over $31 \%$ of enterprises employ less than 10 employees, while more than $51 \%$ have up to 50 employees, whereas around $7 \%$ of the participating enterprises reported that they employ up to 100 employees. Further, in terms of annual sales turnover, over $32 \%$ of the participating enterprises have below 150 thousand USD annual sales turnover, while around $49 \%$ of the enterprises have sales turnover between 150 and 300 thousand USD. Enterprises with over 300 thousand sales turnover account for over $14 \%$. 
Table 1. Composition of sample.

\begin{tabular}{|c|c|}
\hline Region & Percentage \\
\hline Baku & $68.34 \%$ \\
\hline Absheron & $8.54 \%$ \\
\hline Aran & $8.04 \%$ \\
\hline Ganja-Gazakh & $5.53 \%$ \\
\hline Sheki-Zagatala & $5.53 \%$ \\
\hline Guba-Khachmaz & $1.53 \%$ \\
\hline Mountainous Shirvan & $1.53 \%$ \\
\hline Lankaran & $1.02 \%$ \\
\hline Designation of participants & Percentage \\
\hline Owner & $35.45 \%$ \\
\hline Director & $14.05 \%$ \\
\hline Manager & $25.43 \%$ \\
\hline Assistant Manager & $14.48 \%$ \\
\hline Others & $10.59 \%$ \\
\hline Total number of employees & Percentage \\
\hline Less than 10 employees & $31.67 \%$ \\
\hline 10 - 50 employees & $51.41 \%$ \\
\hline 50 - 100 employees & $9.67 \%$ \\
\hline others & $7.25 \%$ \\
\hline Annual Sales Turnover (in dollars) & Percentage \\
\hline Under 150.000 & $32.45 \%$ \\
\hline $150-300$ thousand & $49.34 \%$ \\
\hline 300 thousand -1 million & $14.72 \%$ \\
\hline over 1 million & $3.49 \%$ \\
\hline
\end{tabular}

\section{Results and Discussion}

As expected, the study results indicated that the COVID-19 pandemic had a massive impact on small and medium-sized enterprises operating in Azerbaijan. The diagram below represents the impact of the COVID-19 pandemic on SMEs operating in Azerbaijan and answers the first research question (RQ1) that this paper proposed. Approximately $92.96 \%$ of the enterprises participating in the research study showed that COVID-19 has either extremely negatively or negatively impacted the business operations with $56.78 \%$ and $36.18 \%$ respectively due to lockdown. In comparison, only $3.09 \%$ of the enterprises stated either extremely positive or positive impact of the pandemic on their businesses with $1.64 \%$ and $1.45 \%$ respectively. Only $3.95 \%$ said they did not feel any impact (Figure 1). 


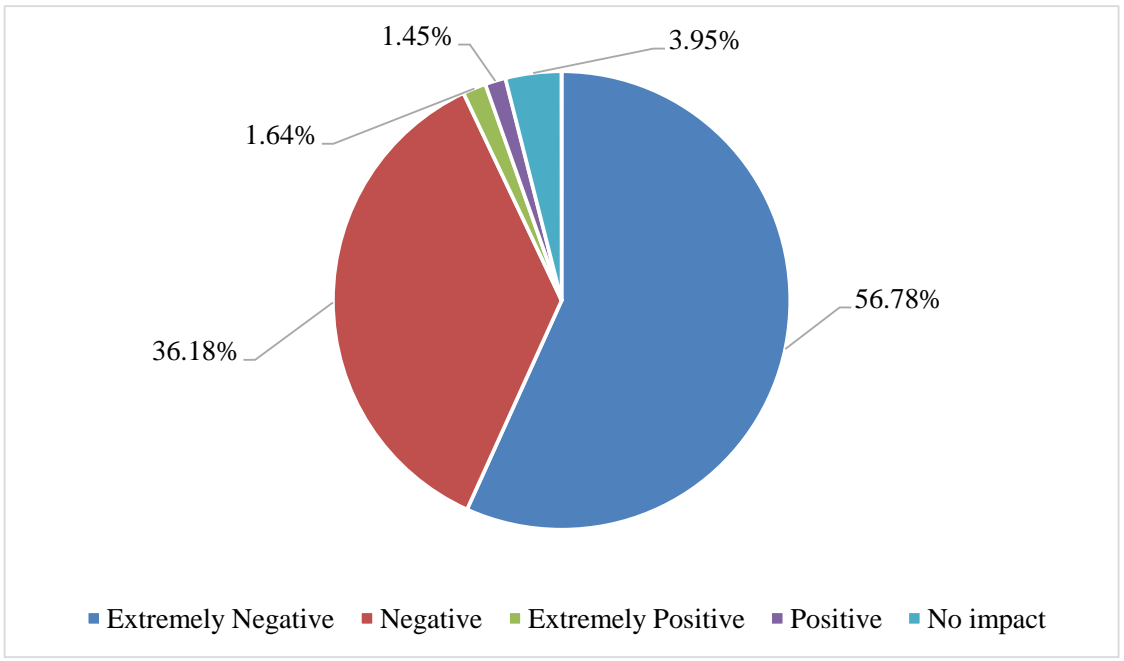

Figure 1. The impact of COVID-19 on SMEs in Azerbaijan.

Based on the changes during lockdown and quarantine measures, $21.61 \%$ of the respondents stated that their business operations ended with the COVID-19 pandemic because of the limited number of customers. Equally, the number of customers who suspended their business operations included $21.61 \%$. Furthermore, based on the number of SMEs operating in the major cities of Azerbaijan, the results of the study indicated that $47.24 \%$ of SMEs continued to work at a reduced pace, and only $9.55 \%$ worked at full capacity.

The diagram below (Figure 2) represents the impact of COVID-19 pandemic on different business sectors in Azerbaijan and answers the second research question (RQ2) that this paper proposed. The results of the survey further show that tourism $(26.60 \%)$, restaurant and cafe sector $(22.10 \%)$ and education sector $(13.60 \%)$ are among the most negatively affected by COVID-19 pandemic while pharmacies $(0.2 \%)$, insurance $(0.8 \%)$ and agriculture $(1.2 \%)$ are among the least affected by the pandemic. The diagram below illustrates the percentages for the other sectors shown in the respondents' responses.

As of the main issues affecting their business operations amid the COVID-19 pandemic, SMEs in major cities of Azerbaijan reported significant problems in finance (65.86\%), decrease in demand (46.03\%), supply chain disruption (48.67\%), and reduction in sales and profit $(37.23 \%)$. The results indicate that many businesses are financially fragile. Moreover, most of the entrepreneurs who participated in study research showed that the demand reduction was primarily due to loss of customers and buyer flow. Therefore, the study results indicated that many SMEs are vulnerable to financial stability, demand constraints, and supply chain disruption.

When asked about government policies and measures taken by the Azerbaijani government to ease the impact of pandemic, $78.39 \%$ of the participants were aware of the government concerns on reviving back the economy and financially supporting small and medium businesses. The remaining respondents, $21.61 \%$, said they were unaware of state support mechanisms. 


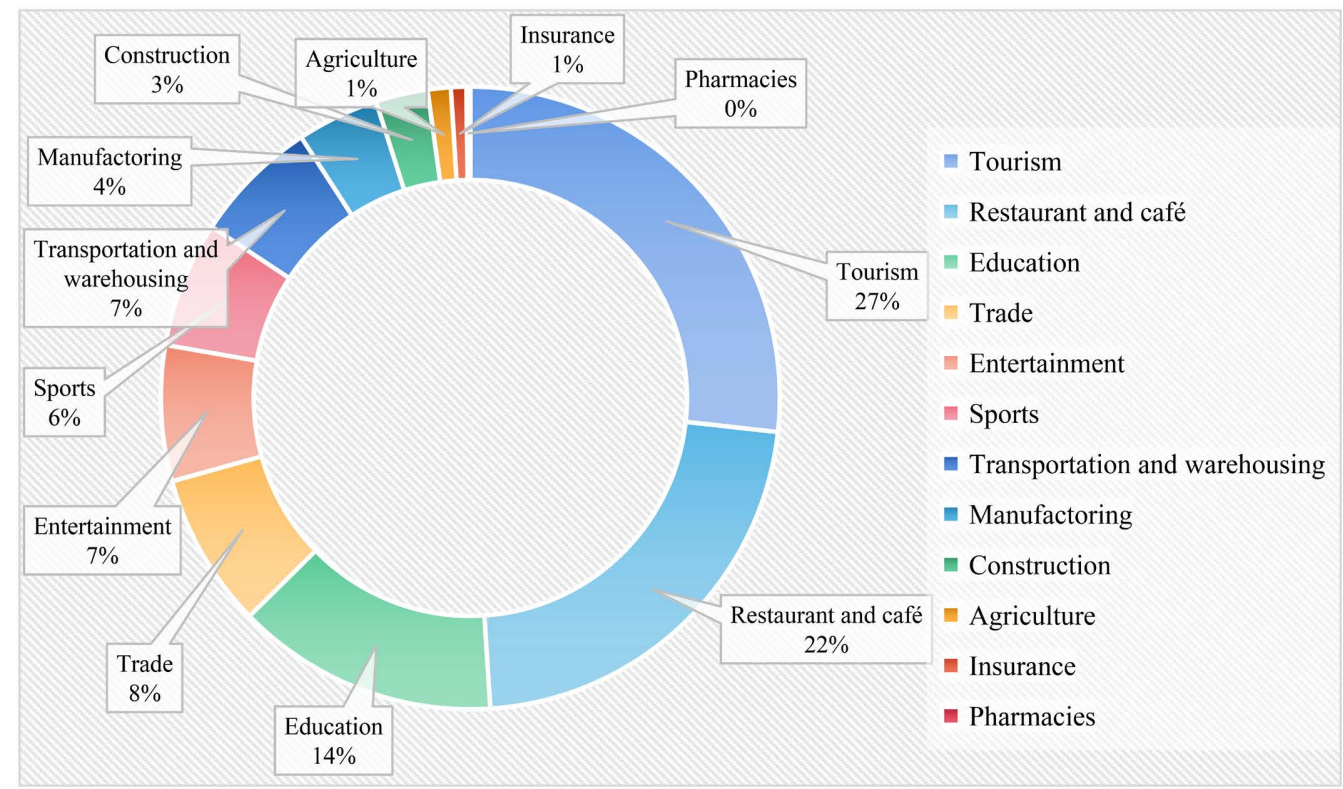

Figure 2. Impact of COVID-19 on different business sectors.

The research study indicated that only $37.69 \%$ of the SMEs were fully satisfied with the government policies and measures adopted to ease the impact of the COVID-19 pandemic on SMEs. $35.68 \%$ were satisfied and $13.07 \%$ were unsatisfied. $2.51 \%$ of respondents said they had difficulties to answer. The survey also found that $94.47 \%$ of the small and medium enterprises need financial support from the Azerbaijan government, however, 5.53\% of the entrepreneurs operating in pharmacies, insurance and agriculture were financially stable and needed no support from the government.

For tax incentives applied by the Azerbaijan government, such as tax breaks and tax holidays, more than half of the entrepreneurs showed positive responses about the government measures to combat the impact of pandemic on SMEs. The research study showed that $20 \%$ of the respondents were not aware of tax incentives applied by the Azerbaijani government to SMEs. Although the majority of respondents were positive about tax incentives, $64.82 \%$ said they did not benefit from them. The remaining respondents, $35.18 \%$, said they benefited from government tax breaks.

\section{Recommendations}

This section answers the third research question (RQ3) as it covers recommendations for policymakers to help SMEs impacted by the pandemic to survive and thrive through COVID-19 and beyond based on questionnaire findings and the available literature on the experience of different countries.

Countries have taken different measures to assist SMEs because of the special situation they are currently facing. While public health is the top priority, a number of initiatives are being implemented to mitigate the COVID-19 pandemic's economic impact on small and medium-sized businesses. "Many governments 
have taken immediate steps in order to help SMEs and self-employed people at this difficult time, with a particular focus on programs in order to maintain the short-term liquidity. These policies come in a variety of shapes and sizes. Some governments have concentrated on more broad-based initiatives that have the ability to soften the economic and business hit. For example, central banks in several countries have intervened to encourage lending by allowing commercial banks to issue additional loans to SMEs and loosening monetary conditions. European Central Bank and The US Federal Reserve, for example, have taken unprecedented actions." (OECD, 2020)

Based on the results of the study, there are various policy measures that Azerbaijani policymakers may adopt to ease the impact of the COVID-19 pandemic on small and medium-sized enterprises. In response, the policy measures cover the following areas:

\section{$\checkmark$ Deferral of taxes, debt payments, social security payments and utility pay- ments}

Deferral of tax is one of the policy measures that Azerbaijani government may take to help SMEs suffered from COVID-19. The most common types of tax deferral are income tax and corporate tax. Deferral of corporate and income tax has been implemented in particular business sectors in some countries. For example, Colombia has established income tax deferral for tourism and aviation industries. The UK will exempt all hospitality, retail and leisure businesses from paying business rates tax for one year in England.

Azerbaijani government may establish income tax deferral for tourism, restaurant and café, and education sector which is the most negatively affected by COVID-19 pandemic according to the findings of this study.

Deferral of social security contributions is another measure Azerbaijani government may take. Measures vary widely due to the large range of social security systems. Deferral is sometimes targeted towards specific industries. In Turkey, entertainment and hospitality sectors, shopping malls, retail, automotive, iron and steel industries, food and beverage firms and textile sectors had been deferred their social security payments for six months.

Some countries have extended deferrals to utility prices (France, Lithuania, Belgium) and rent payments (France, China, Thailand) with the purpose of minimizing liquidity difficulties and costs for enterprises. In some circumstances, these actions are targeted primarily to small and medium sized enterprises.

\section{$\checkmark$ Financial assistance loans}

In Azerbaijan, government authorities should also consider offering disaster financial assistance loans to SMEs that suffered from the COVID-19 pandemic. To ensure affordable repayment, such financial aid loans should be issued at relatively low interest rates with long-term payback terms. Many governments around the world have enacted and expanded policies to encourage commercial banks to lend to small businesses. Reserve requirements for commercial banks have been eased in some countries by central banks, which allow them to expand 
their lending. Governments in Asia and Europe, in particular, have adopted or strengthened bank guarantee systems to help SMEs get loans. China, Japan, South Korea, United Kingdom, France, Austria, Italy, Germany, Belgium, the Netherlands, Denmark are among them. In terms of various measures, the measures include increasing the range of firms and SMEs that are eligible for the guarantees, increasing the proportion of loan guarantees that they apply to as a percentage of the loan, expanding the supply of public funding that supports the guarantees, and also increasing the speed of lending procedure.

\section{$\checkmark$ Subsidies and grants}

Direct financial aid to small businesses has started to spread, with governments, regions, and towns providing grants and subsidies to various local firms. These subsidies can be provided in a number of ways, including a combination of lump-sum payments and tax exemptions. In Chile, for example, an existing program of targeted subsidies for struggling businesses has been extended to tourism businesses from April 2020.

In Belgium, SMEs in need can obtain direct support of between 1300 EURO and 1600 EURO per month. The city of Brussels offers 4000 EURO payout to businesses who had to close their doors (2000 EURO for hairdressers). Companies who must close their doors will receive a payment of 5000 EURO, while companies that must change their opening hours would receive a payout of 2500 EURO. Companies that had to close their doors in Flanders are given a EUR 4000 payout.

\section{$\checkmark$ Structural policy measures}

In some countries, governments have implemented programs to assist small and medium-sized enterprises (SMEs) in implementing new work methods, expediting digitalization, and increasing their market reach. Such short-term approaches are employed to handle acute challenges, but they also aid in the long-term growth of small and medium-sized businesses, strengthening their financial and physical resilience. These are some of the policies that support burgeoning alternative markets, teleworking, and digitization, as well as innovation and workforce training. Due to the fact that SMEs are less inclined to embrace new technology and practices, these policies are essential. Increasing the use of new technology and practices could help businesses improve their postcrisis competitiveness and ability to deal with the challenges posed by megatrends.

The Azerbaijani government should continue stepping forward to prevent the further spread of COVID-19 and limit the restrictions to ease the impact of the COVID-19 pandemic on SMEs. The management of SMEs is recommended to effectively evaluate their cash flow business requirements, reduce unnecessary costs, and formulate plans tackling to prevent further financial risks to the SMEs. The government and other chambers of commerce, such as banks, should offer stimulus packages to address liquidity challenges, avoid the closure of enterprises, and reduce layoffs by meeting with international and local partners. Local 
banks are recommended to take the lion's share in managing the current challenges facing SMEs by facilitating investment criteria and financial opportunities to sustain the existence of small and medium businesses.

\section{Conclusion}

Small and medium-sized businesses have experienced a sharp decline in supply chain disruptions, demand, the shortage of raw materials, transportation of raw materials, cancellation of export orders and delays following the economic recession in Azerbaijan. According to the results of this research, the COVID-19 pandemic has massively affected small and medium-sized enterprises. Approximately $92.96 \%$ of the enterprises participating in the research study showed that COVID-19 has either extremely negatively or negatively impacted the business operations with $56.78 \%$ and $36.18 \%$ respectively due to lockdown. In comparison, only $3.09 \%$ of the enterprises stated either extremely positive or positive impact of the COVID-19 pandemic on their businesses with 1.64\% and 1.45\% respectively. Only 3.95\% said they did not feel any impact. SMEs are facing various issues such as in finance (65.86\%), decrease in demand (46.03\%), supply chain disruption (48.67\%), and reduction in sales and profit $(37.23 \%)$. The results of the survey also showed that tourism $(26.60 \%)$, restaurant and cafe (22.10\%) and education sector (13.60\%) are among the most negatively affected by COVID-19 pandemic while pharmacies $(0.2 \%)$, insurance $(0.8 \%)$ and agriculture (1.2\%) are among the least affected by the pandemic. In addition, the research study indicated that only $37.69 \%$ of the SMEs were fully satisfied with the government policies and measures adopted to ease the impact of the COVID-19 epidemic on SMEs. The survey also found that $94.47 \%$ of the small and medium-sized enterprises need financial support from the Azerbaijan government, however, $5.53 \%$ of the entrepreneurs operating in pharmacies, insurance and agriculture were financially stable and needed no support from the government.

Various policy recommendations were suggested for policymakers to ease the burden on SMEs, based on the research findings. These include deferral of taxes, debt payments, social security payments and utility payments, financial assistance loans, subsidies and grants and structural policy measures. Policymakers wishing to support SMEs, as well as owners and managers of SMEs seeking help in managing their businesses during difficult times, will find research findings and policy recommendations useful.

Although this study has achieved some findings that have insightful theoretical and practical implications for policy makers and SME managers, it has some limitations. The sample size of our study was not enough to represent all industries. Therefore, future research could expand the shortcomings of the current study by increasing sample size with more industries. Furthermore, given the wide range of sectors in which SMEs operate, a sector-based analysis of their practices would be valuable. 


\section{Conflicts of Interest}

The authors declare no conflicts of interest regarding the publication of this paper.

\section{References}

Abasli, I. (2020, September 15). The Socioeconomic Impact of COVID-19 and Oil Price Fluctuations in Azerbaijan. https://ge.boell.org/en/2020/09/15/socioeconomic-impact-covid-19-and-oil-price-fluct uations-azerbaijan

Akbulaev, N., Mammadov, I., \& Aliyev, V. (2020). Economic Impact of COVID-19. (July 13, 2020). SYLWAN, 164, 1-14. https://ssrn.com/abstract=3649813 https://doi.org/10.2139/ssrn.3649813

Albonico, M., \& Sharma, R. (2020). How the COVID-19 Crisis Is Affecting UK Small and Medium-Size Enterprises. McKinsey \& Company.

Bayramov, V., Hasanov, R., Aghayarli, L., Kadyrov, Z., Aghahasanli, I., \& Isayev, S. (2017). A Comparative Study on Development of Small and Medium Enterprises (SMEs) in Azerbaijan. https://ssrn.com/abstract $=3485576$

https://doi.org/10.2139/ssrn.3485576

BDC (2020). Survey on the Impact of COVID-19 on Canadian SMEs.

https://www.bdc.ca/globalassets/digizuite/17305-survey-impact-of-covid19-on-canadia n-smes.pdf? $v=4 \mathrm{a} 475 \mathrm{f}$

Enesi, O., \& Ibrahim, U. (2021) Effect of COVID-19 Pandemic on the Performance of Small and Medium Business Enterprises in Abuja-FCT, Nigeria. Open Journal of Business and Management, 9, 2261-2276. https://doi.org/10.4236/ojbm.2021.95122

Hoorens, S., Hocking, L., \& Fays, C. (2020). How Small Businesses Are Coping with the Impact of COVID-19 (pp. 1-19). RAND Corporation.

Juergensen, J., Guimón, J., \& Narula, R. (2020). European SMEs Amidst the COVID-19 Crisis: Assessing Impact and Policy Responses. Journal of Industrial and Business Economics, 47, 499-510. https://doi.org/10.1007/s40812-020-00169-4

Mahmudova, L. (2019). Overview of Small and Medium Entrepreneurship in Azerbaijan. Network Intelligence Studies, 7, 13-20.

Maulana, A. (2020, April 24). Studies on COVID-19 and Its Impact. European Cluster Collaboration Platform.

https://clustercollaboration.eu/achievements/studies-covid-19-and-its-impact

Muller, P., Robin, N., Jessie, W., Schroder, J., Braun, H., Becker, L. S. et al. (2019). Annual Report on European SMEs 2018/2019-Research \& Development and Innovation by SMEs. European Union.

OECD (Organisation for Economic Co-Operation and Development) (2020). SME Policy Index: Eastern Partner Countries 2020: Assessing the Implementation of the Small Business Act for Europe, SME Policy Index, European Union, Brussels. OECD Publishing, Paris.

UNDP Turkey (2020, April 8). Four in Every Five SMEs Substantially Impacted by COVID-19 Crisis!

https://www.tr.undp.org/content/turkey/en/home/presscenter/pressreleases/2020/04/B $\underline{4 \mathrm{G} \text {-anket.html }}$

World Health Organization (WHO) (2021, June).

https://covid19.who.int/region/euro/country/az 